\title{
Protein encapsulation in polymeric microneedles by photolithography
}

This article was published in the following Dove Press journal:

International Journal of Nanomedicine

21 June 2012

Number of times this article has been viewed

Jaspreet Singh Kochhar'

Shui Zou²

Sui Yung Chan'

Lifeng Kang'

'Department of Pharmacy,

${ }^{2}$ Department of Chemistry, National

University of Singapore, Singapore

Video abstract

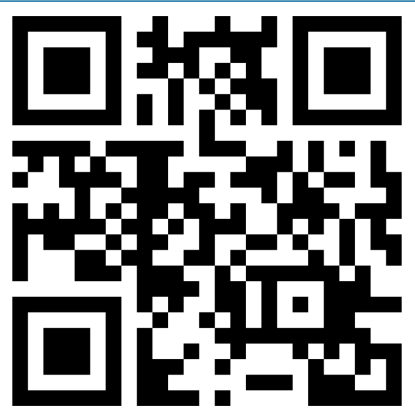

Point your SmartPhone at the code above. If you have a QR code reader the video abstract will appear. Or use: http://dypr.es/KAo2dy

Correspondence: Lifeng Kang Department of Pharmacy, National University of Singapore, 18 Science

Drive 4, Singapore II 7543

Tel +6565167519

$\mathrm{Fax}+656779 \quad 1554$

Email lkang@nus.edu.sg
Background: Recent interest in biocompatible polymeric microneedles for the delivery of biomolecules has propelled considerable interest in fabrication of microneedles. It is important that the fabrication process is feasible for drug encapsulation and compatible with the stability of the drug in question. Moreover, drug encapsulation may offer the advantage of higher drug loading compared with other technologies, such as drug coating.

Methods and results: In this study, we encapsulated a model protein drug, namely, bovine serum albumin, in polymeric microneedles by photolithography. Drug distribution within the microneedle array was found to be uniform. The encapsulated protein retained its primary, secondary, and tertiary structural characteristics. In vitro release of the encapsulated protein showed that almost all of the drug was released into phosphate buffered saline within 6 hours. The in vitro permeation profile of encapsulated bovine serum albumin through rat skin was also tested and shown to resemble the in vitro release profile, with an initial release burst followed by a slow release phase. The cytotoxicity of the microneedles without bovine serum albumin was tested in three different cell lines. High cell viabilities were observed, demonstrating the innocuous nature of the microneedles.

Conclusion: The microneedle array can potentially serve as a useful drug carrier for proteins, peptides, and vaccines.

Keywords: poly (ethylene glycol) diacrylate, microneedles, protein stability, photolithography, biocompatibility

\section{Introduction}

Transdermal drug delivery has seen a rapid growth in the past three decades. Since the approval of a scopolamine transdermal patch in 1979, researchers have developed a variety of transdermal dosage forms, leading to 21 transdermal drugs being approved by the US Food and Drug Administration. ${ }^{1}$ Simultaneously, the growth of biotechnology has produced a surge in the number of protein and peptide drugs available for human use. $^{2}$ Most of these protein drugs have been conventionally delivered via intravenous or subcutaneous routes, necessitating frequent injections, thus reducing patient compliance. Oral delivery of proteins, peptides, and vaccines is envisaged, but there are significant hurdles due to the adverse environment these biomolecules encounter in the gastrointestinal tract. ${ }^{3}$ Transdermal delivery has evolved as an interesting alternative for protein drug therapy because it circumvents the inherent challenges associated with oral and parenteral routes. However, the skin's natural barrier prevents these macromolecules from diffusing through the skin. 
To enhance their permeation, active permeation methodologies have been used. Chemical penetration enhancers as well as physical techniques like electroporation, ultrasound, and iontophoresis have seen some success. ${ }^{4,5}$ Microneedles have been shown to disrupt the stratum corneum actively by creating micron-sized pores and hence enhancing the flux of macromolecules.$^{6-8}$ They offer the advantage of delivering a drug without impinging on the underlying nerves. ${ }^{9}$

Drugs have been delivered using microneedles by three different modes. Firstly, coating onto microneedle shafts, ${ }^{10,11}$ and secondly, pretreating the skin with microneedles to create pores, followed by application of conventional dosage forms. ${ }^{12,13}$ With the development of polymeric microneedles, a third approach was developed whereby drugs could be encapsulated in the polymeric matrix and released from the polymer upon application. ${ }^{14}$ Encapsulation of drugs within the polymeric core offers the advantage of a higher drug loading in one convenient formulation, omitting multiple steps that would otherwise be required. Hence encapsulation of drugs within the microneedles has received most attention from transdermal drug delivery scientists in the past few years. ${ }^{15-17}$

Encapsulation of proteins inside microscale and nanoscale particles has been studied previously using various approaches, such as double emulsion, ${ }^{18}$ electrospray, ${ }^{19}$ selfassembly, ${ }^{20}$ and microfabrication. ${ }^{21}$ For example, lipid nanocarriers of the self-assembled type can be used to encapsulate proteins, peptides, and nucleic acids with tunable sizes and morphologies..$^{20,22}$ These three-dimensional nanostructures can be obtained by homogenizing a mixture of lipids hydrated with protein solutions.

Similarly, therapeutic proteins such as insulin and vaccines can be encapsulated in microneedles, from which release of these proteins has been demonstrated upon insertion into animal skins in vivo. ${ }^{14,23,24} \mathrm{~A}$ compilation of proteins and vaccines that can be potentially delivered through the skin has been reviewed by Prausnitz and Langer. ${ }^{4}$ Drugs released from microneedles can form a depot from where they can be absorbed into the systemic circulation or lymphatic vessels. Drugs have been encapsulated in microneedles by various techniques, including micromolding the drug-containing polymer in prefabricated master structures ${ }^{17,25}$ or dipping polypropylene tips in drug-laden polymer solutions. ${ }^{24}$ Photo crosslinking of drug-laden polymer precursors filled in preformed molds using ultraviolet light has also been reported. ${ }^{14,23}$

However, the reported fabrication approaches used for these protein-laden microneedles involve the use of high temperatures, vacuum, or prolonged exposure to ultraviolet light which may be potentially harmful to biological drugs.
High temperatures $\left(140^{\circ} \mathrm{C}-160^{\circ} \mathrm{C}\right)$ used for micromolding of sugar microneedles have resulted in a significant loss of drug content. ${ }^{26}$ Casting methods used by other groups ${ }^{25,27}$ utilize polymers or sugar derivatives requiring a concentration of hydrogel using high temperatures and vacuum which may have deleterious effects on fragile protein molecules. ${ }^{26}$ A newer process reported recently involves prefabrication of a female purple sand mold at high temperatures and subsequent fabrication of needles by vacuum suction and freeze-drying. ${ }^{28}$ These challenging conditions may not be ideal for a drug delivery system aimed to encapsulate fragile molecules.

We have recently developed a photolithography-based method utilizing low exposure to ultraviolet light, ${ }^{29}$ which can be potentially applied for protein encapsulation. We selected bovine serum albumin (BSA) as a model protein. To ensure that the encapsulated material retains its structure and activity, we tested the stability of the encapsulated BSA by analyzing its primary, secondary, and tertiary structural features. This is relevant for therapeutic proteins and peptide drugs like insulin, desmopressin, and vaccines, such as influenza vaccine. To the best of our knowledge, this is the first report detailing exhaustive stability testing for protein encapsulation in microneedles. The in vitro release of the BSA protein was tested in phosphate-buffered saline. In vitro permeation of the encapsulated BSA through rat skin was also tested. In addition, we report the in vitro biocompatibility of microneedles using three different cell lines to assess the toxicity of the polymeric microneedles for skin applications.

\section{Materials and methods Materials}

Poly (ethylene glycol) diacrylate (PEGDA) $(\mathrm{Mn}=258)$, 2-hydroxy-2-methyl propiophenone, and BSA were purchased from Sigma-Aldrich (St Louis, MO). 3-(4,5-dimethylthiazol2-yl)-2,5-diphenyl tetrazolium bromide (MTT) and dimethyl sulfoxide were purchased from MP Biomedicals (Cleveland, $\mathrm{OH})$. A CytoTox-ONETM homogeneous membrane integrity assay kit was bought from Promega (Madison, WI). Sodium azide was purchased from Alfa Aesar (Lancaster, UK). BSA Texas red conjugate was bought from Molecular Probes, Invitrogen (Orlando, FL). All other chemicals were of analytical grade and used as received.

\section{Fabrication and characterization of polymeric microneedles}

The microneedles were fabricated by a photolithographic method we developed previously. ${ }^{29}$ Briefly, PEGDA containing 
$0.5 \% \mathrm{v} / \mathrm{v}$ of 2-hydroxy-2-methyl propiophenone, hereinafter referred to as "prepolymer" solution, was exposed to a high intensity $\left(20.9 \mathrm{~W} / \mathrm{cm}^{2}\right)$ ultraviolet light source (Exfo Omnicure, Quebec, Canada) to form the backing layer. In a similar step, the prepolymer solution was pipetted onto this backing layer and exposed to ultraviolet light through a specifically patterned photomask. The microstructures thus formed, due to preferential exposure of the prepolymer solution in transparent regions of the photomask, represented micron-sized rods, defined as "microneedles". Excess unpolymerized prepolymer solution was washed away using purified water and the microneedles left to dry in air. The geometric characteristics of the microneedles (length, base, and tip diameter) were studied using an SMZ-1500 stereomicroscope (Nikon, Tokyo, Japan).

\section{Incorporation and uniform drug distribution in microneedles}

BSA Texas red conjugate was incorporated into the microneedle backing layer and shafts at a concentration of $0.045 \% \mathrm{w} / \mathrm{w}$ in the prepolymer solution to ascertain uniform distribution of drug in the polymerized microneedles. The fabricated microstructures were then imaged using a Nikon A-1R confocal microscope to observe the fluorescence intensity at various areas of the backing layer and various lengths of a microneedle shaft. The fluorescence intensity was calculated using Nikon NIS elements BR 3.1 analytical software. Microneedle arrays were also imaged with a Nikon SMZ-1500 stereomicroscope.

\section{Stability tests for BSA in microneedles} Primary structure stability

Sodium dodecyl sulfate-polyacrylamide gel electrophoresis was carried out using Laemmli's method to assess the effect of ultraviolet-initiated photopolymerization on the conformational stability of BSA. ${ }^{30}$ It was performed by casting $10 \%$ running gel and $5 \%$ stacking gel. Each formulation, containing $10 \mu \mathrm{g}$ of protein sample as determined by bicinchoninic acid protein assay (Pierce, Rockford, IL), was mixed with an equal quantity of Laemmli sample buffer and $5 \%$ of $\beta$-mercaptoethanol. The solutions were heated at $100^{\circ} \mathrm{C}$ for 2 minutes after which they were loaded onto a comb stacked on the gel cast in an electrophoresis cell. The gel was run at 100 volts for 2.5 hours. After removal from the electrophoresis cell, the gel was stained with Coomassie brilliant blue R-250 staining solution for 2 hours on an orbital shaker. The excess stain was removed by a destaining solution (20\% methanol, $10 \%$ glacial acetic acid, 70\% water) overnight and the gel was imaged using a Samsung ST-550 digital camera (Seoul, South Korea).

\section{Secondary structure stability}

Circular dichroism spectroscopy was performed on the samples to evaluate the secondary structural characteristics of BSA in the fabricated microneedles. The analysis was performed using a Jasco J-810 spectropolarimeter (Tokyo, Japan) with a $1 \mathrm{~mm}$ light path quartz cell (Hellma, Müllheim, Germany). Data were acquired at a bandwidth of $0.1 \mathrm{~nm}$ with a scan speed of $50 \mathrm{~nm}$ per minute and a response time of 8 seconds. The samples and standard BSA solution were scanned over the wavelength range of 240-200 $\mathrm{nm}$. The microneedle release samples were first filtered using microcentrifugal concentrators, (30 kDa cutoff, Vivaspin 20, General Electric, Addlestone, Surrey, UK) to separate the protein from the polymer. The samples were compared with a standard solution of BSA, and BSA degraded using heat $\left(75^{\circ} \mathrm{C}\right)$ and acidic conditions $(\mathrm{pH} 2)$ was used as a control. ${ }^{31,32}$ The average value of triplicate measurements was used to plot the curve of mean residue ellipticity (in degrees $\mathrm{cm}^{2} \mathrm{dmol}^{-1}$ ) to wavelength. The experimental data acquired from the spectropolarimeter were analyzed using the DichroWeb browser and a deconvolution algorithm (K2d) to calculate the mean residue ellipticity and percentage of alpha helix. ${ }^{33-35}$

\section{Tertiary structure stability}

In order to evaluate tertiary structural changes in the protein conformation, their fluorescence spectra were analyzed. A standard BSA solution at a concentration of $0.026 \mathrm{mg} / \mathrm{mL}$ in purified water was prepared to compare the spectral data with the BSA released from the microneedle samples. The emission spectra were studied in the range of $300-400 \mathrm{~nm}$ at a fixed excitation wavelength of $280 \mathrm{~nm}$ using a Hitachi F-7000 fluorescence spectrophotometer (Hitachi, Japan). Similar to the circular dichroism experiments, heat-degraded and aciddegraded samples were used as a control. The fluorescence intensities were plotted against wavelength as an average of triplicate measurements.

\section{In vitro release of BSA from microneedles}

BSA was encapsulated in the microneedles at three different concentrations $(0.5 \%, 0.8 \%$, and $1.3 \% \mathrm{w} / \mathrm{w}$ BSA in prepolymer solution) to obtain microneedle arrays containing $0.4-1.6 \mathrm{mg}$ of the protein. The in vitro release was 
determined by suspending the microneedle arrays in $15 \mathrm{~mL}$ of $1 \times$ phosphate buffered saline at $37^{\circ} \mathrm{C}$. Periodically, the release medium was withdrawn completely and replaced with $15 \mathrm{~mL}$ of fresh medium to maintain sink conditions. The collected samples were kept at $4^{\circ} \mathrm{C}$ until analysis. The protein concentration in the release samples was analyzed by a bicinchoninic acid protein assay kit. Each concentration was analyzed in triplicate and the mean value was used for analysis. The cumulative amount in mg and the percentage of BSA released were plotted against time.

\section{In vitro permeation through rat skin}

In vitro permeation studies were carried out in water jacketed horizontal diffusion cells (TK-6H1, Shanghai Kai Kai Science and Technology Co Ltd, Shanghai, China). The skin was hydrated in the receptor solution $(1 \times$ phosphate-buffered saline with $0.005 \% \mathrm{v} / \mathrm{v}$ sodium azide) overnight. The skin was placed stretched on ten layers of Kimwipes (Kimberly-Clark, Roswell, GA) to provide tissue-like mechanical support. ${ }^{36}$ Microneedles containing $0.7 \%, 1.42 \%$, and $1.85 \% \mathrm{w} / \mathrm{w}$ BSA were applied to abdominal rat skin after removing the subcutaneous fat. Microneedles containing no BSA were used to blank the inherent protein released from the skin. BSA dissolved in propylene glycol was used to compare the enhancement of BSA permeation by microneedles over passive diffusion. The microneedle array was secured on the skin using scotch tape and the skin was placed between the donor and receptor compartments. The receptor compartment was filled with $4.5 \mathrm{~mL}$ of receptor solution, which was continuously stirred at $250 \mathrm{rpm}$ using a Teflon-coated magnetic stirrer. At each sampling point, $1 \mathrm{~mL}$ of receptor solution was withdrawn and replaced with fresh receptor solution. The collected samples were stored at $4^{\circ} \mathrm{C}$ until they were analyzed. All samples were centrifuged at 10,000 rpm for 5 minutes and the supernatant was collected for analysis. The concentration of permeated BSA was determined by the ultraviolet $\mathrm{A}_{215}-\mathrm{A}_{225}$ method. ${ }^{37}$ Each sample was analyzed in triplicate. The cumulative amount of drug permeated per unit area was plotted against time.

\section{In vitro biocompatibility of polymeric microneedles}

Biocompatibility of the microneedle materials was assessed by the viability of three different cell lines using colorimetric determination of mitochondrial succinate dehydrogenase activity using the MTT assay. ${ }^{38}$ Human dermal fibroblasts, human adult low calcium high temperature (HaCaT) keratinocytes, and human embryonic kidney (HEK293) cells were used to assess the toxicity of the polymer used in fabricating the microneedles. The cells were grown in Dulbecco's modified Eagle's medium supplemented by $10 \%$ fetal bovine serum and 1\% penicillin-streptomycin solution. After the cells had achieved 80\%-90\% confluency, they were trypsinized and counted. Cells $\left(1 \times 10^{4}\right.$ cells/well $)$ were plated into 96-well microtiter plates (Corning, NY) in $200 \mu \mathrm{L}$ of growth medium. After 24 hours of plating, $20 \mu \mathrm{L}$ of polymer extracts (prepared by extracting the polymer from fabricated microneedles in $1 \times$ phosphate-buffered saline at $37^{\circ} \mathrm{C}$ for 24 hours) were added to each well. Positive control consisted of wells containing $20 \mu \mathrm{L} 1 \times$ phosphate-buffered saline. The plates were incubated at $37^{\circ} \mathrm{C}$ in humidified $5 \%$ $\mathrm{CO}_{2}$ for 24,48 , and 72 hours. The medium was aspirated at the respective analysis point, and $20 \mu \mathrm{L}$ of MTT solution ( $5 \mathrm{mg} / \mathrm{mL}$ in phosphate-buffered saline) was added to each well, followed by $200 \mu \mathrm{L}$ of growth medium. The plates were incubated for 4 hours at $37^{\circ} \mathrm{C}$. After 4 hours, the medium was aspirated again and $150 \mu \mathrm{L}$ of dimethyl sulfoxide was added into each well to dissolve the formazan crystals formed, with the aid of a plate shaker operated at $100 \mathrm{rpm}$. The colorimetric assay was carried out by measuring the absorbance at $595 \mathrm{~nm}$ using a Tecan 2000 microplate reader (Tecan, Germany). The cell viabilities were calculated as a percentage of the control.

The toxicity of the polymer was also assessed by analyzing the amount of lactate dehydrogenase released from the membranes of damaged cells. ${ }^{39}$ The cells were plated in a similar manner as described above and treated with polymer extract and phosphate-buffered saline. Maximum lactate dehydrogenase release was achieved by treating the cells with the lysis solution ( $9 \% \mathrm{w} / \mathrm{v}$ Triton $\mathrm{X}-100)$ provided by the manufacturer. The assay was performed according to the manufacturer's protocol. The percentage toxicity was calculated using the following equation, where Polymer ${ }_{\text {LDH }}$, Vehicle $_{\mathrm{LDH}}$, and Triton ${ }_{\mathrm{LDH}}$ represent the respective fluorescence values obtained from wells treated with polymer, phosphate-buffered saline, and Triton X-100.

$$
\text { Cytotoxicity }(\%)=\frac{\text { Polymer }_{\mathrm{LDH}}-\text { Vehicle }_{\mathrm{LDH}}}{\text { Triton }_{\mathrm{LDH}}-\text { Vehicle }_{\mathrm{LDH}}} \times 100
$$

\section{Statistical analysis}

The graphs were plotted using Microsoft Excel 2007. All experiments were performed at least three times and the data are reported as the mean \pm standard deviation. Statistical analysis of the data was performed using PASW Statistics 18 Software (SPSS Inc, Chicago, IL). Comparison 
amongst groups was made by analysis of variance. The difference was considered to be statistically significant at $P<0.05$.

\section{Results and discussion \\ Fabrication and characterization of microneedles}

The microneedles were found to have an average length of $820 \mu \mathrm{m}$, a base diameter of $300 \mu \mathrm{m}$, a center to center spacing between the needles of $1500 \mu \mathrm{m}$, and an average tip diameter of $140 \mu \mathrm{m}$. The microneedle patch consisted of an array of $8 \times 8$ needles spread over an area of $1.44 \mathrm{~cm}^{2}$.

\section{Incorporation and uniform drug distribution in microneedles}

Drug incorporation in the polymeric matrix prior to microneedle formation allows for higher drug loading as opposed to coating the drug molecules on the fabricated microneedles. In this study, we could achieve up to $1.6 \mathrm{mg}$ of BSA per microneedle array. Drug encapsulation in polymers has been used previously with other polymers, namely, polyvinyl pyrrolidone and its copolymer with methacrylic acid, ${ }^{23}$ copolymer of methylvinylether and maleic anhydride, ${ }^{40}$ and polyvinyl alcohol. ${ }^{41}$ However, our method circumvents the long ultraviolet exposure and extensive preprocessing required for microneedle formation using the previous methods, which may impact protein stability. Moreover, our process does not involve any mold-based or template-based processing, potentially avoiding interactions between mold or template material and fragile protein molecules.

An important aspect of a drug delivery system is the uniform distribution of drug in the carrier matrices. To test for uniformity, we encapsulated BSA Texas red conjugate to visualize the distribution of the protein inside the backing and the shafts of the microneedle array. The BSA Texas red conjugate shows peak excitation $\left(\lambda_{\mathrm{ex}}\right)$ and emission $\left(\lambda_{\mathrm{em}}\right)$ at $596 \mathrm{~nm}$ and $615 \mathrm{~nm}$, respectively, ${ }^{42}$ which can be quantified using fluorescence microscopy. We employed confocal imaging as a tool to image the microneedle sample to assess the fluorescence distribution at different areas and depths of the microstructure. As observed from Figure 1A and D, fluorescence is distributed across different areas of the backing layer in a uniform pattern $(P>0.05)$. However, as the microneedle length increased from the bottom of the array (length $10 \mu \mathrm{m}$ ) to the microneedle tip (length $700 \mu \mathrm{m}$ ), the fluorescence intensity was observed to decrease gradually from 377 to 3.1 (Figure 1B and E). This can be attributed to the inherent microneedle geometry because the microneedle shafts are broader at the base than at the tip, owing to less drug being encapsulated in the tip region of the microneedles. Drug distribution among different microneedles in an array was constant, with the majority of the microneedles showing a uniform fluorescence (Figure 1F). This is expected to ensure uniform drug delivery over the patch area of $1.44 \mathrm{~cm}^{2}$. Figure $1 \mathrm{C}$ shows a stereomicroscope image of a complete microneedle array, showing that the drug is evenly distributed.

\section{Stability tests for BSA in microneedles}

Microneedles have been considered as a useful drug delivery system to deliver therapeutic peptides, proteins, and vaccines. ${ }^{4}$ Because the biological function of a protein is dependent on its conformation, it is imperative to design a dosage form which does not adversely affect the stability of these fragile molecules. In our fabrication process, we used an ultraviolet light-based photo cross-linking method for creating polymeric microstructures. Ultraviolet light has been previously reported to cause protein denaturation and structural changes in the primary, secondary, and tertiary structure of proteins. ${ }^{43}$ We studied these three structural features by investigating sodium dodecyl sulfate polyacrylamide gel electrophoresis, circular dichroism spectra, and fluorescence intensity measurements of BSA encapsulated in the microneedles. While the results here demonstrate that the conformation of BSA was maintained throughout the fabrication process and the subsequent release experiments, the structural and biological properties of proteins other than BSA will depend on individual protein characteristics.

Sodium dodecyl sulfate polyacrylamide gel electrophoresis has been the most common method used for the separation of proteins and determination of protein molecular weight. ${ }^{44,45}$ It has been used previously to determine the structural integrity of BSA in microspheres. ${ }^{46}$ In this study, we used sodium dodecyl sulfate polyacrylamide gel electrophoresis to determine the amino acid sequence of BSA and analyze any deleterious effect of ultraviolet radiation on the protein (Figure 2). BSA released from the formulation was compared with a freshly prepared solution and a protein standard marker. The single line of bands appearing at $66 \mathrm{kDa}$ suggests that the protein was stable during the fabrication process and remained stable in the dosage form for a period of 72 hours. There were no other bands observed during the electrophoretic separation, providing evidence against any protein aggregation to form dimer or multimer or fragmentation to smaller subunits, indicating the primary structure of BSA remained intact during the fabrication process. 

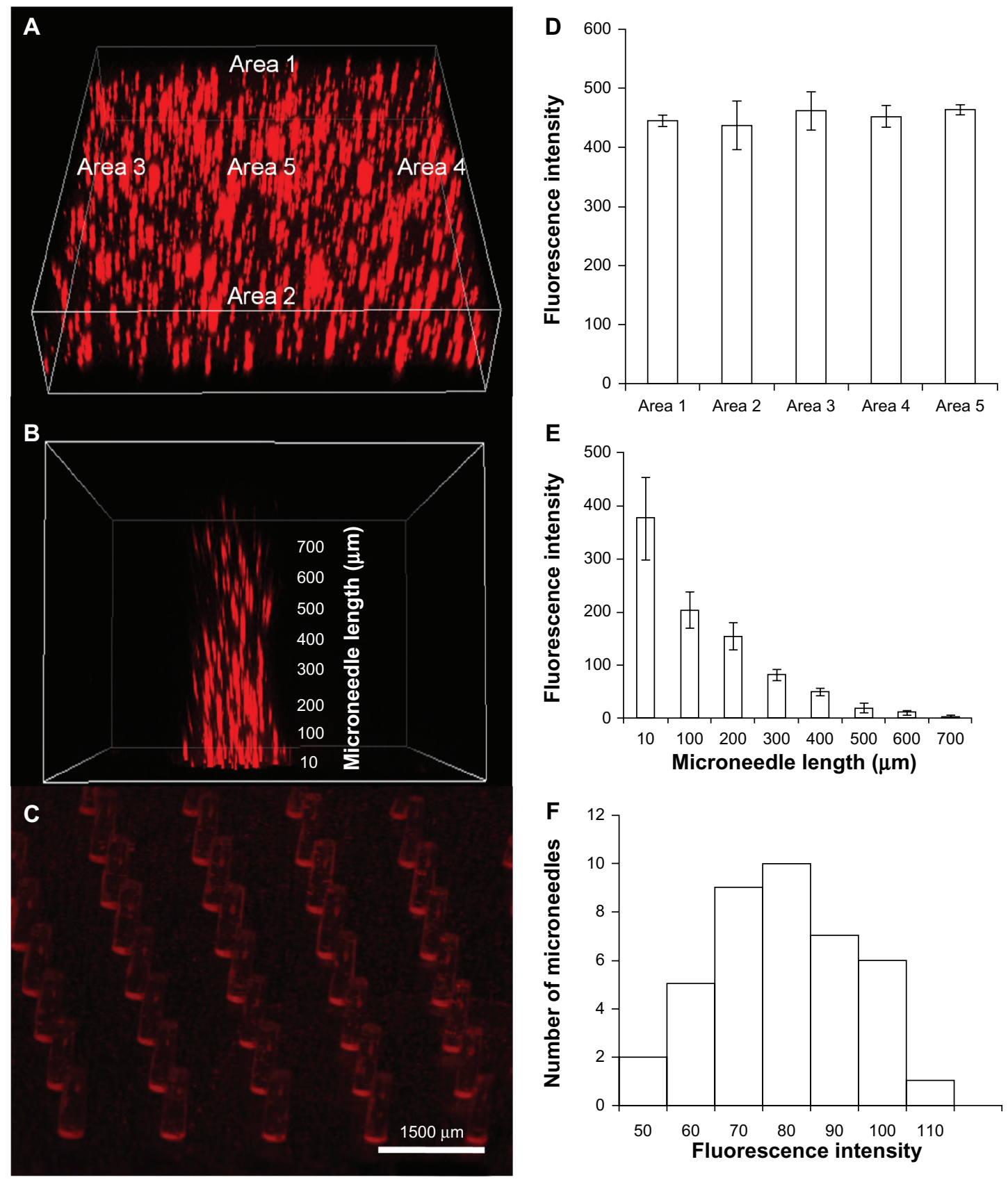

Figure I Encapsulation of bovine serum albumin Texas red conjugate (TR-BSA) in polymeric microstructures shows uniform distribution. Uniformly distributed TR-BSA in (A) microneedle backing and (B) microneedle shaft (C) microneedle array. Quantitative estimation of fluorescence intensity shows uniform distribution over (D) different areas of the backing layer $(n=3),(E)$ different length on a microneedle shaft $(n=6)$ and $(\mathbf{F})$ different microneedles of an array.

The secondary structure of BSA was assessed by circular dichroism. BSA contains $67 \%$ of $\alpha$-helix, $10 \%$ of turn, and no $\beta$-sheet. ${ }^{31}$ The far ultraviolet circular dichroism spectrum (260-200 nm) has been used to characterize the structural stability of BSA. ${ }^{47}$ The $\alpha$-helix structure is indicated by two negative peaks at $208 \mathrm{~nm}$ and $222 \mathrm{~nm}$ with a minimum peak at $208 \mathrm{~nm}$, which is attributed to $\mathrm{n} \rightarrow \pi^{*}$ and $\pi \rightarrow \pi^{*}$ transition of the $\alpha$-helix structure. ${ }^{48,49}$ It was observed that the secondary structure of BSA encapsulated in the microneedles was similar to a freshly prepared solution of BSA, as shown in Figure 3A. The degraded BSA used as a control showed significantly lower ellipticity values than the standard BSA and microneedle release samples. The percentage of $\alpha$-helix from the microneedle release samples was consistent with the reported amount of helix in the native BSA structure (about 67\%). ${ }^{50}$ The percentage of $\alpha$-helix in the BSA released from the microneedle samples was comparable with the standard $(P>0.05$, Figure $3 \mathrm{~B})$ and significantly different 


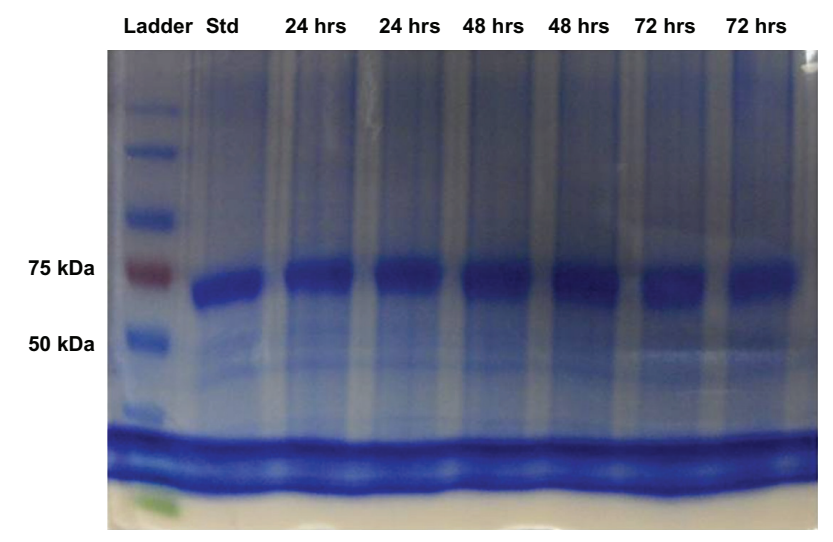

Figure 2 Sodium dodecyl sulphate-polyacrylamide gel electrophoresis images of protein standard marker, bovine serum albumin standard and bovine serum albumin released from microneedles after 24,48 , and 72 hours.

from heat-denatured and acid-denatured BSA samples $(P<0.05)$. Circular dichroism analysis has been similarly reported for lysozyme. ${ }^{25}$ These results demonstrated that secondary structural integrity of BSA was maintained during ultraviolet-dependent photopolymerization.

Because proteins contain aromatic amino acids like tyrosine, tryptophan, and phenylalanine, which are inherently fluorescent, fluorescence spectra and intensity can be used as a marker of protein structural stability. Tryptophan is the most dominant fluorophore and displays the largest extinction coefficient. Thus, the emission spectra of proteins can be measured at a fixed excitation wavelength of $280 \mathrm{~nm} .^{51}$ The emission maximum of tryptophan in water is observed around $350 \mathrm{~nm}$ and is dependent on the polarity of the solvent. BSA emission spectra were scanned between $300 \mathrm{~nm}$ and
$400 \mathrm{~nm}$ and an emission maximum was observed at $338 \mathrm{~nm}$ for all the release samples and a standard solution of BSA (Figure 4). This is in accordance with previously reported results $^{52}$ and demonstrates the feasibility of our fabrication process for retaining protein stability in the microneedles. On the other hand, BSA samples denatured using heat or acid did not show any fluorescence (excitation wavelength 280 and emission wavelength $300-400 \mathrm{~nm}$ ).

The analysis of primary, secondary, and tertiary structural stability of BSA demonstrated the microneedles to be a potentially useful carrier for protein drugs. The ultraviolet photo cross-linking did not significantly alter the structural properties of BSA, possibly due to the short time of exposure.

\section{In vitro release of BSA from microneedles}

The release profile of BSA is depicted in Figure 5A (percentage release) and Figure 5B (cumulative amount). We used phosphate-buffered saline ( $\mathrm{pH}$ 7.4) as a release medium because it closely resembles extracellular fluids and plasma. It was observed that $80 \%-100 \%$ of the protein encapsulated in the microneedle array was released within a period of 6 hours. Most of the protein was encapsulated in the microneedle backing layer (about 90\%) and the needles owing to their micron-scale geometry containing less drug. Similar release kinetics were observed in previous reports. ${ }^{27}$

The transient pores created by microneedles and diffusion of the protein through the polymeric layer to the epidermal and dermal regions to create a depot of protein drugs have been implicated. ${ }^{10,53}$ The drugs can be subsequently absorbed
A

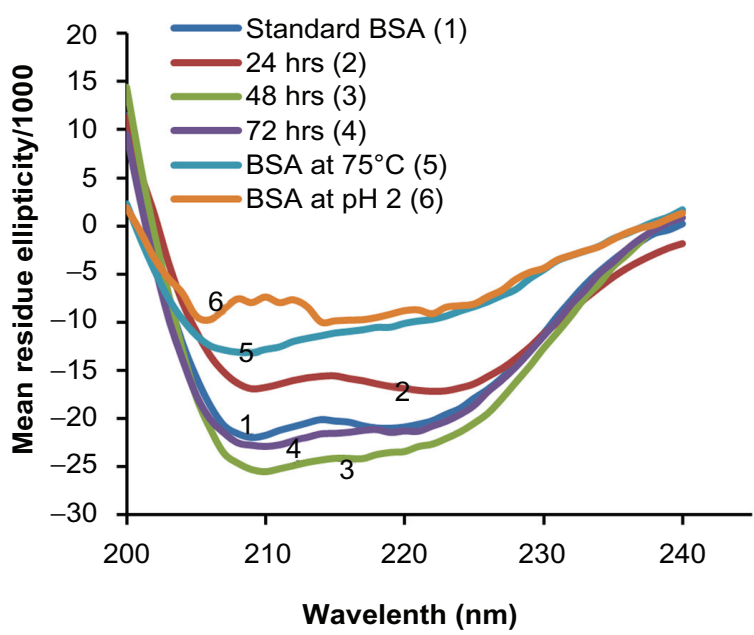

B

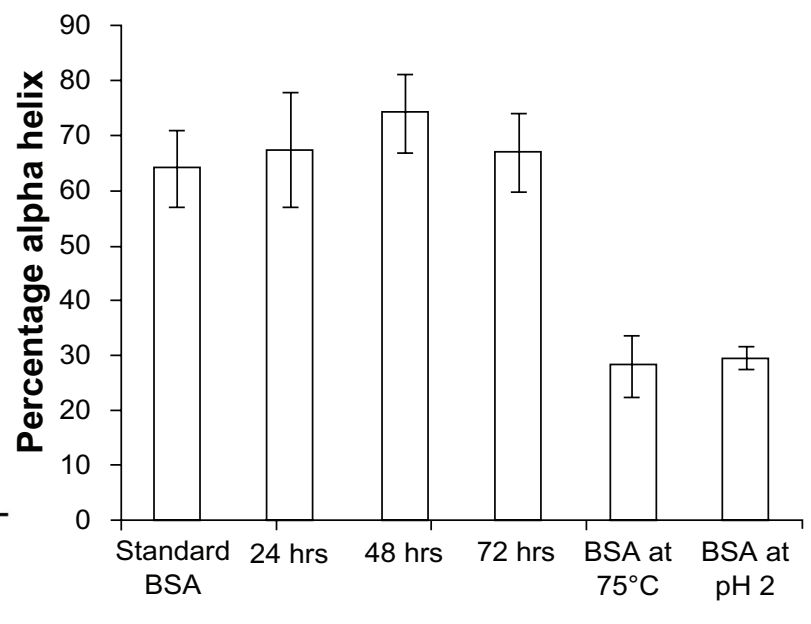

Figure 3 Circular dichroism analysis to assess the stability of encapsulated bovine serum albumin (BSA). Stability of BSA released from microneedles after storage for 3 days at $37^{\circ} \mathrm{C}$ is compared with a freshly prepared BSA solution and BSA degraded by heating at $75^{\circ} \mathrm{C}$ and under acidic conditions, pH 2 (A) mean residue ellipticity and (B) percentage of alpha-helix. All results confirmed the alpha helix structure of BSA was preserved during encapsulation and release over a period of 3 days. 


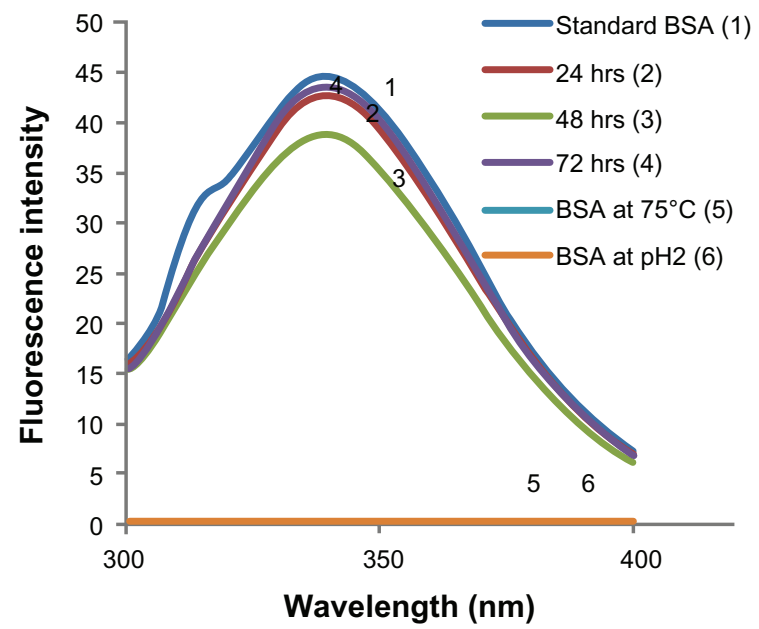

Figure 4 Fluorescence spectroscopic analysis to assess the tertiary structure of encapsulated bovine serum albumin (BSA). Stability of BSA released from microneedles after storage for $1-3$ days at $37^{\circ} \mathrm{C}$ is compared with freshly prepared BSA solution and BSA degraded by heating at $75^{\circ} \mathrm{C}$ and under acidic conditions, $(\mathrm{pH} 2)$ by analyzing the emission spectra of BSA. Peak BSA emission wavelength was found to be similar for all samples. No fluorescence was observed in degraded BSA samples.

into the blood stream or lymphatic circulation. ${ }^{11,54}$ It is expected that the protein released will accumulate in the subepidermal tissues and be rapidly absorbed from the highly vascularized regions lying underneath.

\section{In vitro permeation through rat skin}

Microneedles increased the amount of BSA permeated as compared with passive diffusion of BSA. Because BSA is a large molecule (66 kDa), it cannot diffuse passively through the skin. Figure 6 shows the increase in the cumulative amount permeated per unit area on microneedle application as compared with a propylene glycol solution of BSA, which showed practically no permeation at the end of 48 hours. The amount permeated in the case of microneedles increased with the increase in the encapsulated amount of BSA. The permeation curve resembles the in vitro release profile observed in phosphate-buffered saline, with an initial burst-release followed by a slow-release phase. A similar BSA permeation pattern has been reported previously. ${ }^{37}$ Other protein molecules, like fluorescein isothiocyanate-labeled BSA and insulin, incorporated in polymeric microneedles have also shown such burst-release patterns. ${ }^{40}$ Such permeation profiles are common for other highly water-soluble drugs, such as calcein $(\log P=-5.02)$. However, we observed in our previous studies that relatively lipophilic drugs (eg, rhodamine $\mathrm{B}, \log P=2.43$ ) do not show a burst in permeation and their absorption is somewhat limited by interaction with stratum corneum lipids. $^{29}$

The $\mathrm{A}_{215}-\mathrm{A}_{225}$ method has been previously used in determining the BSA concentration in in vitro permeation studies. ${ }^{37}$ The concentration of BSA is a linear function of the difference between extinction at $215 \mathrm{~nm}$ and $225 \mathrm{~nm} .^{55}$ The method is sensitive for protein concentrations as low as $5 \mathrm{ng} / \mathrm{mL}$, which are usually expected in in vitro permeation studies. The protein concentration was calculated using the following equation:

$$
\text { BSA concentration }(\mu \mathrm{g} / \mathrm{mL})=144 \times\left(\mathrm{A}_{215}-\mathrm{A}_{225}\right)
$$

Microneedles containing no BSA were used as a control to minimize any absorption from the dissolved polymer. When lower amounts of BSA were encapsulated, the permeation curve demonstrated a plateau at nearly 18 hours, because most of the drug was released. When higher amounts were encapsulated, the protein continued to be released for 2 days, suggesting that the microneedle array developed in the study is amenable to dose adjustment as per the requirements of the therapeutic
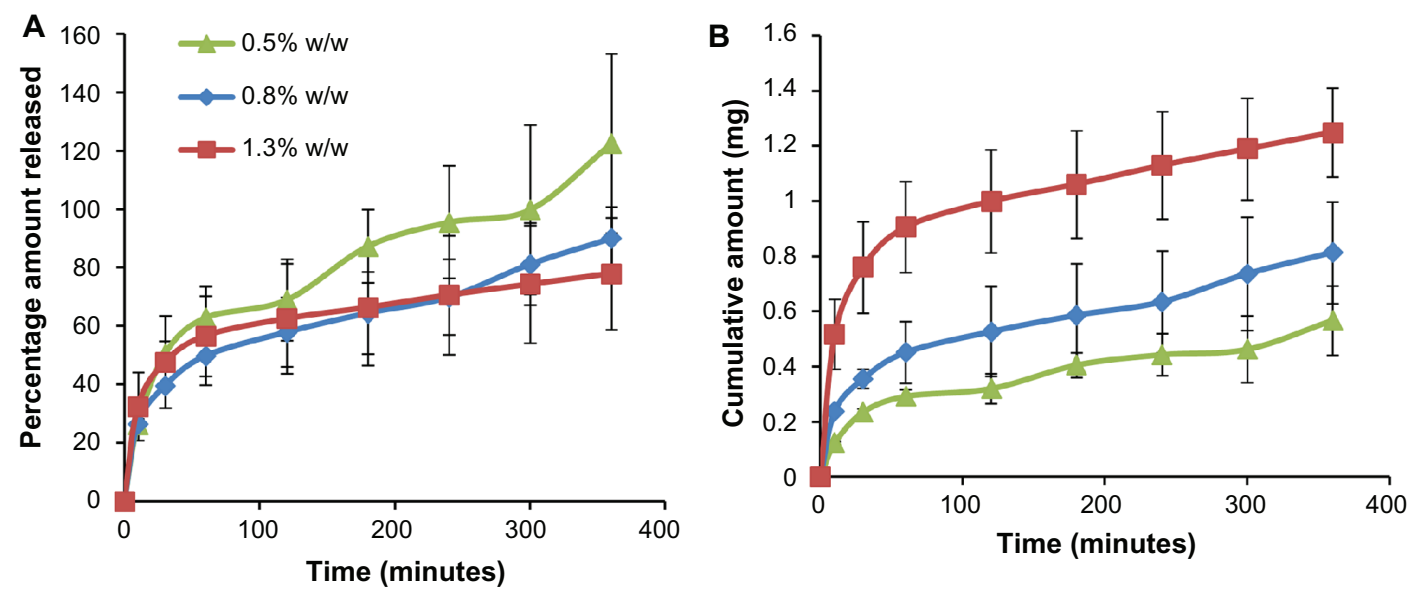

Figure 5 Release profile of bovine serum albumin encapsulated in microneedles over a period of 6 hours. (A) Percentage amount and (B) cumulative amount released. 

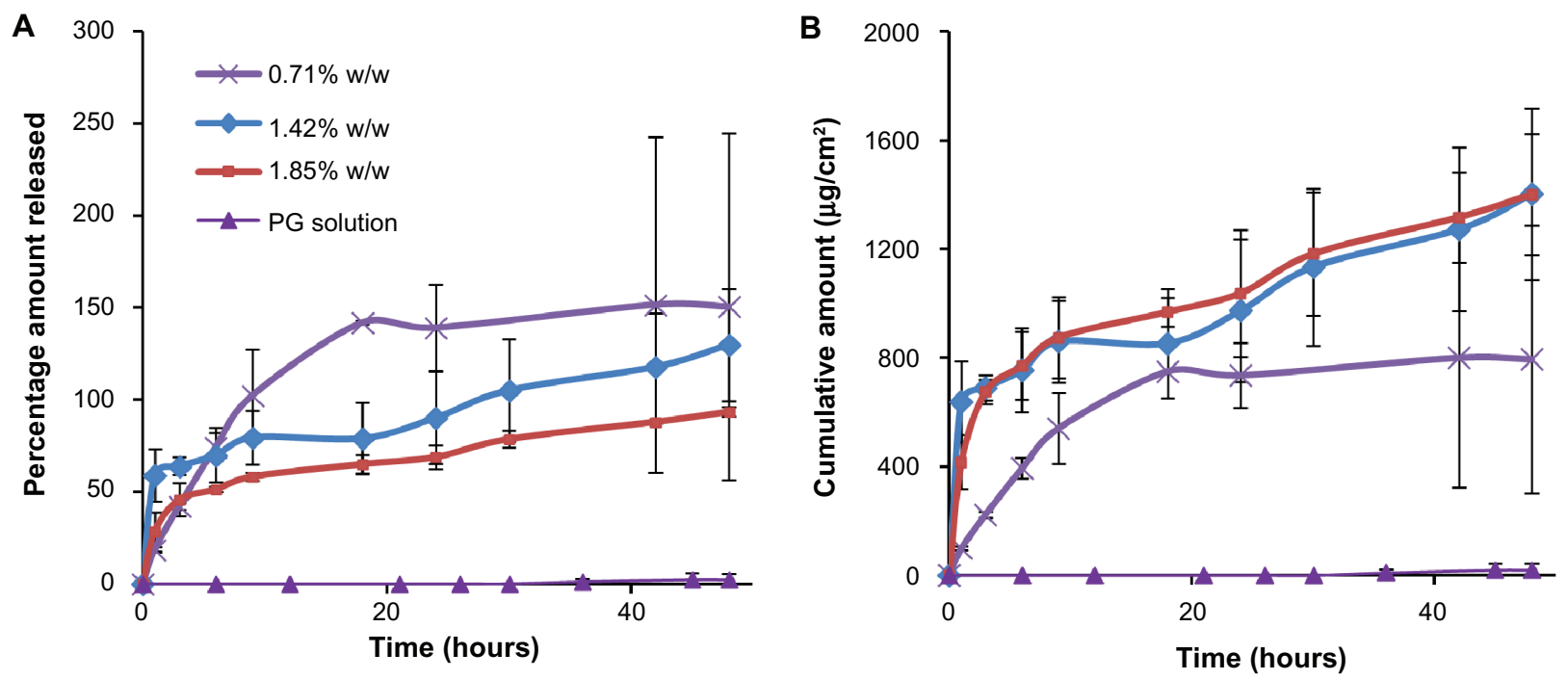

Figure 6 In vitro permeation through rat skin. (A) Percentage amount and (B) cumulative amount permeated through rat skin when applied with a microneedle patch (containing $0.71 \%-1.85 \% \mathrm{w} / \mathrm{w}$ bovine serum albumin) or a propylene glycol solution of bovine serum albumin over a period of $48 \mathrm{hours}$.

regimen. As compared with microneedles, passive diffusion of BSA using a propylene glycol solution did not result in any significant amount of drug permeation through the skin.

Conventional skin permeation where steady state can be established is based on the fact that the donor concentration is constant throughout the diffusion process. This can be proven by Fick's first law for membrane diffusion. ${ }^{5}$ However, in this study, the donor concentration decreased during the permeation process. Moreover, it is not a pure membrane diffusion process because micropassages were created by these microneedles, making the process a combination of diffusion through the skin membrane and mass transport through micron-sized channels across skin.

\section{In vitro biocompatibility of polymeric microneedles}

Human dermal fibroblasts and $\mathrm{HaCaT}$ keratinocytes are representative of skin cells and hence were used to assess the toxicity of the polymeric microdevice on the skin. These cells have been used previously to study the toxicity of transdermal polymeric dosage forms. ${ }^{56,57}$ HEK293 cells were used because they are representative of healthy human cells. HEK293 cells have been used in numerous in vitro toxicity studies as being representative of human cells since they offer a convenient model to evaluate toxicity at the cellular level..$^{58}$ They have also been previously reported with regard to transdermal toxicity from topical gels. ${ }^{59}$ Using three different cells, we aimed to assess the local and systemic biocompatibility of our novel polymeric microneedles.

The MTT assay was used to assess the toxicity of microneedle extracts to these cells. Viable cells, possessing the active mitochondrial succinate-tetrazolium reductase system reduce MTT to formazan crystals which were quantified by colorimetric determination. ${ }^{59}$ The cell viabilities were calculated as $\mathrm{A}_{\text {polymer }} / \mathrm{A}_{\text {control }} \times 100$, where $\mathrm{A}_{\text {polymer }}$ and $\mathrm{A}_{\text {control }}$ were the absorbance measurements of the wells containing polymeric extracts and control (phosphate-buffered saline), respectively. Each value was an average of six replicates.
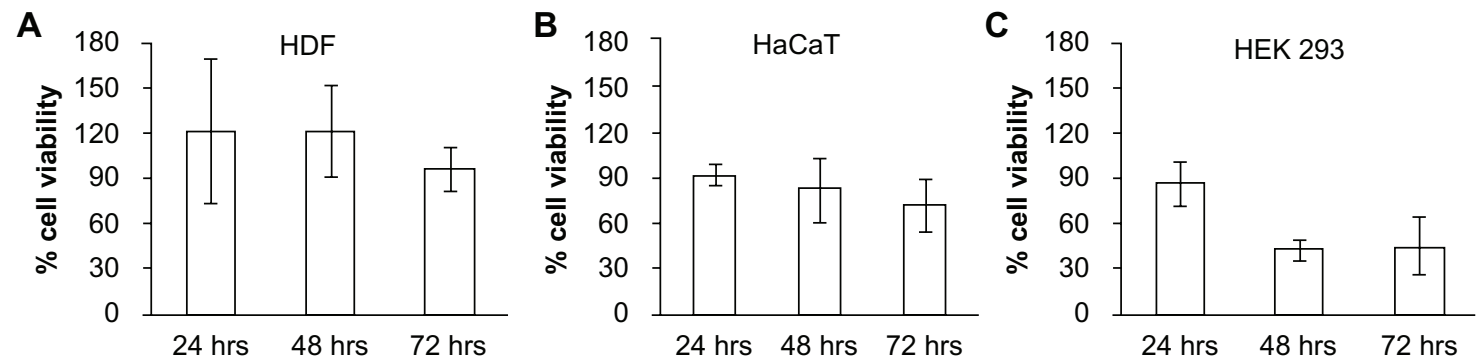

Figure 7 In vitro biocompatibility testing using MTT assay in (A) human dermal fibroblasts (HDF), (B) human adult low calcium high temperature (HaCaT) cells, and (C) human embryonic kidney 293 (HEK293) cells demonstrated high cell viability, indicating the biocompatibility of polymerized PEGDA microneedles. 

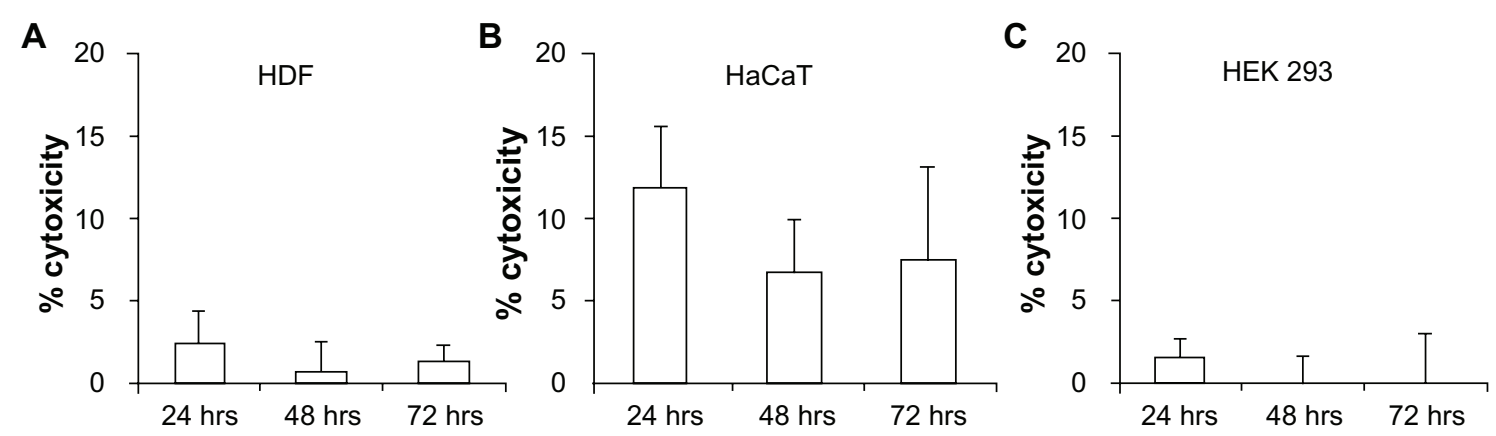

Figure 8 In vitro cytotoxicity testing using lactate dehydrogenase assay in (A) human dermal fibroblasts (HDF), (B) human adult low calcium high temperature (HaCaT) cells, and (C) human embryonic kidney 293 (HEK293) cells demonstrated low toxicity, indicating the biocompatibility of PEGDA microneedles.

High cell viabilities with respect to the control were found for human dermal fibroblasts and $\mathrm{HaCaT}$ cells for exposure of cells to polymeric extracts up to 72 hours (Figure $7 \mathrm{~A}$ and B), with cell survival numbers statistically insignificant between 24 and 72 hours $(P>0.05)$. This shows that the polymer used for fabricating the microneedles was safe to skin locally. HEK293 cell viability assays yielded similar viability for the first 24 hours, which subsequently decreased $(P<0.05$, Figure 7C). However, it has been reported that PEGDA with a molecular weight less than 20,000 Da can be cleared rapidly via the kidney by dissolution in body fluids. ${ }^{60}$ Hence we expect minimal systemic toxicity due to PEGDA owing to its rapid clearance.

Fluorometric determination of lactate dehydrogenase leaked out from damaged cell membranes into the supernatant medium has been accepted as a method to determine the cytotoxicity of compounds and has been previously used for polymers as well.$^{61}$ In our study, low cell toxicities were observed in all the three cell lines for cells treated with polymer extracts. The percentage cytotoxicity for cells treated from 24-72 hours did not vary significantly $(P>0.05)$, supporting the results from the MTT assay and further proving the biocompatibility of polyethylene glycol diacrylate (Figure 8A-C). Overall, the in vitro toxicity results showed promising biocompatibility of the polymeric microneedles, both transdermally and systemically.

\section{Conclusion}

We have demonstrated the amenability of our photilithographic technique to encapsulate protein drugs. Drug distribution was found to be uniform across the microneedle array. Moreover, the process was proven to maintain protein stability and is hence expected to retain the biological activity of the encapsulated proteins. The encapsulated protein was released and permeated through the skin in much larger amounts as compared with passive diffusion. In vitro biocompatibility of the polymeric microneedles has been demonstrated by the low cytotoxicity of the polymeric extracts on different cell lines, indicating the safety of these microneedles. In conclusion, the prepared microneedles are expected to serve as a potentially useful drug delivery system to deliver biological drugs.

\section{Acknowledgments}

The authors would like to acknowledge Joleen Lim for her assistance with imaging the microneedle samples. We also thank Sathya Unudurthi, Sandeep Shelar, and Jun Yan for their help with the experiments in this study, and Brian W Dymock for his careful proofreading. We would also like to thank Joyce Lee and Aparna Saigal for their assisstance in preparation of the video abstract. Jaspreet Singh is the recipient of a National University of Singapore research scholarship. This study was supported by a startup grant from the National University of Singapore.

\section{Disclosure}

The authors report no conflicts of interest in this work.

\section{References}

1. Food and Drug Administration. Approved Drug Products with Therapeutic Equivalence Evaluations. 31st ed. Rockville, MD: US Department of Health and Human Services; 2011.

2. Daugherty AL, Mrsny RJ. Emerging technologies that overcome biological barriers for therapeutic protein delivery. Exp Opin Biol Ther. 2003;3(7):1071-1081.

3. Ahad A, Aqil M, Kohli K, et al. Chemical penetration enhancers: a patent review. Expert Opin Ther Pat. 2009;19(7):969-988.

4. Prausnitz MR, Langer R. Transdermal drug delivery. Nat Biotechnol. 2008;26(11):1261-1268

5. Kang L, Yap CW, Lim PF, et al. Formulation development of transdermal dosage forms: quantitative structure-activity relationship model for predicting activities of terpenes that enhance drug penetration through human skin. J Control Release. 2007;120(3):211-219.

6. Gill HS, Prausnitz MR. Coated microneedles for transdermal delivery. J Control Release. 2007;117(2):227-237.

7. Ito Y, Murakami A, Maeda T, Sugioka N, Takada K. Evaluation of selfdissolving needles containing low molecular weight heparin (LMWH) in rats. Int J Pharm. 2008;349(1-2):124-129. 
8. Donnelly RF, Majithiya R, Singh TR, et al. Design, optimization and characterisation of polymeric microneedle arrays prepared by a novel laser-based micromoulding technique. Pharm Res. 2011;28(1):41-57.

9. Kaushik S, Hord AH, Denson DD, et al. Lack of pain associated with microfabricated microneedles. Anesth Analg. 2001;92(2):502-504.

10. Jiang J, Gill HS, Ghate D, et al. Coated microneedles for drug delivery to the eye. Invest Ophthalmol Vis Sci. 2007;48(9):4038-4043.

11. Koutsonanos DG, del Pilar Martin M, Zarnitsyn VG, et al. Transdermal influenza immunization with vaccine-coated microneedle arrays. PLoS One. 2009;4(3):e4773.

12. Kumar A, Li X, Sandoval MA, et al. Permeation of antigen proteinconjugated nanoparticles and live bacteria through microneedle-treated mouse skin. Int J Nanomedicine. 2011;6:1253-1264.

13. Baek C, Han M, Min J, Prausnitz MR, Park JH. Local transdermal delivery of phenylephrine to the anal sphincter muscle using microneedles. J Control Release. 2011;154(2):138-147.

14. Sullivan SP, Koutsonanos DG, Del Pilar Martin M, et al. Dissolving polymer microneedle patches for influenza vaccination. Nat Med. 2010;16(8):915-920.

15. You XQ, Chang JH, Ju BK, Pak JJ. Rapidly dissolving fibroin microneedles for transdermal drug delivery. Mater Sci Eng C Mater Biol Appl. 2011;31(8):1632-1636.

16. Ito Y, Kashiwara S, Fukushima K, Takada K. Two-layered dissolving microneedles for percutaneous delivery of sumatriptan in rats. Drug Dev Ind Pharm. 2011;37(12):1387-1393.

17. Migalska K, Morrow DI, Garland MJ, et al. Laser-engineered dissolving microneedle arrays for transdermal macromolecular drug delivery. Pharm Res. 2011;28(8):1919-1930.

18. Panyam J, Dali MM, Sahoo SK, et al. Polymer degradation and in vitro release of a model protein from poly(D,L-lactide-co-glycolide) nano- and microparticles. J Control Release. 2003;92(1-2):173-187.

19. Xie J, Wang CH. Encapsulation of proteins in biodegradable polymeric microparticles using electrospray in the Taylor cone-jet mode. Biotechnol Bioeng. 2007;97(5):1278-1290.

20. Angelova A, Angelov B, Mutafchieva R, Lesieur S, Couvreur P. Self-assembled multicompartment liquid crystalline lipid carriers for protein, peptide, and nucleic acid drug delivery. Acc Chem Res. 2011;44(2):147-156.

21. Pan J, Chan SY, Lee WG, Kang L. Microfabricated particulate drugdelivery systems. Biotechnol J. 2011;6(12):1477-1487.

22. Angelova A, Ollivon M, Campitelli A, Bourgaux C. Lipid cubic phases as stable nanochannel network structures for protein biochip development: X-ray diffraction study. Langmuir. 2003;19(17):6928-6935.

23. Sullivan SP, Murthy N, Prausnitz MR. Minimally invasive protein delivery with rapidly dissolving polymer microneedles. Adv Mater. 2008;20(5):933-938.

24. Ito Y, Hagiwara E, Saeki A, Sugioka N, Takada K. Feasibility of microneedles for percutaneous absorption of insulin. Eur J Pharm Sci. 2006;29(1):82-88

25. Lee JW, Park JH, Prausnitz MR. Dissolving microneedles for transdermal drug delivery. Biomaterials. 2008;29(13):2113-2124.

26. Donnelly RF, Morrow DIJ, Singh TRR, et al. Processing difficulties and instability of carbohydrate microneedle arrays. Drug Dev Ind Pharm. 2009;35(10):1242-1254

27. Park JH, Allen MG, Prausnitz MR. Polymer microneedles for controlled-release drug delivery. Pharm Res. 2006;23(5):1008-1019.

28. Yang S, Feng Y, Zhang L, et al. A scalable fabrication process of polymer microneedles. Int J Nanomedicine. 2012;7:1415-1422.

29. Kochhar JS, Goh WJ, Chan SY, Kang L. A simple method of microneedle array fabrication for transdermal drug delivery. Drug Dev Ind Pharm. April 23, 2012. [Epub ahead of print.]

30. Laemmli UK. Cleavage of structural proteins during the assembly of the head of bacteriophage T4. Nature. 1970;227(5259):680-685.

31. Murayama K, Tomida M. Heat-induced secondary structure and conformation change of bovine serum albumin investigated by Fourier transform infrared spectroscopy. Biochemistry. 2004;43(36): 11526-11532.
32. Estey T, Kang J, Schwendeman SP, Carpenter JF. BSA degradation under acidic conditions: a model for protein instability during release from PLGA delivery systems. J Pharm Sci. 2006;95(7):1626-1639.

33. Whitmore L, Wallace BA. Protein secondary structure analyses from circular dichroism spectroscopy: methods and reference databases. Biopolymers. 2008;89(5):392-400.

34. Whitmore L, Wallace BA. DICHROWEB, an online server for protein secondary structure analyses from circular dichroism spectroscopic data. Nucleic Acids Res. 2004;32(Web Server issue):W668-W673.

35. Andrade MA, Chacon P, Merelo JJ, Moran F. Evaluation of secondary structure of proteins from UV circular dichroism spectra using an unsupervised learning neural network. Protein Eng. 1993;6(4): 383-390.

36. Park JH, Allen MG, Prausnitz MR. Biodegradable polymer microneedles: fabrication, mechanics and transdermal drug delivery. J Control Release. 2005;104(1):51-66.

37. Xie Y, Xu B, Gao Y. Controlled transdermal delivery of model drug compounds by MEMS microneedle array. Nanomedicine. 2005;1(2):184-190.

38. Mosmann T. Rapid colorimetric assay for cellular growth and survival: application to proliferation and cytotoxicity assays. J Immunol Methods. 1983;65(1-2):55-63.

39. Berckmans P, Leppens H, Vangenechten C, Witters H. Screening of endocrine disrupting chemicals with MELN cells, an ER-transactivation assay combined with cytotoxicity assessment. Toxicol In Vitro. 2007;21(7):1262-1267.

40. Garland MJ, Caffarel-Salvador E, Migalska K, Woolfson AD, Donnelly RF. Dissolving polymeric microneedle arrays for electrically assisted transdermal drug delivery. $J$ Control Release. 2012;159(1):52-59.

41. Gonzalez-Gonzalez E, Speaker TJ, Hickerson RP, et al. Silencing of reporter gene expression in skin using siRNAs and expression of plasmid DNA delivered by a soluble protrusion array device (PAD). Mol Ther. 2010;18(9):1667-1674.

42. Titus JA, Haugland R, Sharrow SO, Segal DM. Texas red, a hydrophilic, red-emitting fluorophore for use with fluorescein in dual parameter flow microfluorometric and fluorescence microscopic studies. J Immunol Methods. 1982;50(2):193-204.

43. Kerwin BA, Remmele RL Jr. Protect from light: photodegradation and protein biologics. J Pharm Sci. 2007;96(6):1468-1479.

44. Weber K, Osborn M. The reliability of molecular weight determinations by dodecyl sulfate-polyacrylamide gel electrophoresis. J Biol Chem. 1969;244(16):4406-4412.

45. He Y, Yeung ES. Rapid determination of protein molecular weight by the Ferguson method and multiplexed capillary electrophoresis. J Proteome Res. 2002;1(3):273-277.

46. Çetin M, Vural I, Çapan Y, Hincal AA. Preparation and characterization of BSA-loaded alginate microspheres. Fabad J Pharm Sci. 2007;32(3):103-107.

47. Husband FA, Garrood MJ, Mackie AR, Burnett GR, Wilde PJ. Adsorbed protein secondary and tertiary structures by circular dichroism and infrared spectroscopy with refractive index matched emulsions. J Agric Food Chem. 2001;49(2):859-866.

48. Price NC. Conformational issues in the characterization of proteins. Biotechnol Appl Biochem. 2000;31(Pt 1):29-40.

49. Hu X, Cui S, Liu J. Fluorescence studies of interaction between flavonol p-coumaroylglucoside tiliroside and bovine serum albumin. Spectrochim Acta A Mol Biomol Spectrosc. 2010;77(2):548-553.

50. Zhuang W, Li L, Lin G, Deng Z, Peng M. Ilaprazole metabolites, ilaprazole sulfone and ilaprazole sulfide decreased the affinity of ilaprazole to bovine serum albumin. J Lumin. 2012;132(2):350-356.

51. Lakowicz JR. Protein fluorescence. In: Lakowicz JR, editor. Principles of Fluorescence Spectroscopy. New York, NY: Springer; 2006.

52. Tan L, Liu L, Xie Q, Zhang Y, Yao S. Fluorescence quenching of bovine serum albumin in reversed micelles by CdS nanoparticles. Anal Sci. 2004;20(3):441-444.

53. Park JH, Allen MG, Prausnitz MR. Polymer microneedles for controlled-release drug delivery. Pharm Res. 2006;23(5):1008-1019. 
54. Harvey AJ, Kaestner SA, Sutter DE, et al. Microneedle-based intradermal delivery enables rapid lymphatic uptake and distribution of protein drugs. Pharm Res. 2011;28(1):107-116.

55. Aitken A, Learmonth MP. Protein determination by UV absorption. In: Walker JM, editor. The Protein Protocols Handbook. New Jersey, NJ: Humana Press Inc; 2002.

56. Mangalathillam S, Rejinold NS, Nair A, et al. Curcumin loaded chitin nanogels for skin cancer treatment via the transdermal route. Nanoscale. 2011;4(1):239-250.

57. Maupas C, Moulari B, Beduneau A, Lamprecht A, Pellequer Y. Surfactant dependent toxicity of lipid nanocapsules in HaCaT cells. Int J Pharm. 2011;411(1-2):136-141.
58. Goncharuk V, Nezheradze K, Datskevich E. The use of HEK 293 human cells for assessing water toxicity before and after purification of ions of copper and zinc. J Water Chem Tech. 2010;32(1):50-55.

59. Rozman B, Zvonar A, Falson F, Gasperlin M. Temperature-sensitive microemulsion gel: an effective topical delivery system for simultaneous delivery of vitamins C and E. AAPS Pharm Sci Tech. 2009;10(1): 54-61.

60. Varghese S, Elisseeff JH. Hydrogels for musculoskeletal tissue engineering. Adv Polym Sci. 2006;203:95-144.

61. Hipler UC, Schonfelder U, Hipler C, Elsner P. Influence of cyclodextrins on the proliferation of HaCaT keratinocytes in vitro. J Biomed Mater Res A. 2007;83(1):70-79.

\section{Publish your work in this journal}

The International Journal of Nanomedicine is an international, peerreviewed journal focusing on the application of nanotechnology in diagnostics, therapeutics, and drug delivery systems throughout the biomedical field. This journal is indexed on PubMed Central, MedLine, CAS, SciSearch $\AA$, Current Contents ${ }^{\circledR} /$ Clinical Medicine,
Journal Citation Reports/Science Edition, EMBase, Scopus and the Elsevier Bibliographic databases. The manuscript management system is completely online and includes a very quick and fair peer-review system, which is all easy to use. Visit http://www.dovepress.com/ testimonials.php to read real quotes from published authors. 